\title{
Ethnologies
}

\section{Storytelling: Interdisciplinary and Intercultural Perspectives. By Irene Maria F. Blayer and Monica Sanchez, eds. (New York: Peter Lang, 2002. Pp. xi + 321, ISBN 0-8204-5125-8)}

\section{J. Joseph Edgette}

Volume 28, numéro 2, 2006

Les noces en vrai

Wedding Realities

URI : https://id.erudit.org/iderudit/014991ar

DOI : https://doi.org/10.7202/014991ar

Aller au sommaire du numéro

\section{Éditeur(s)}

Association Canadienne d'Ethnologie et de Folklore

ISSN

1481-5974 (imprimé)

1708-0401 (numérique)

Découvrir la revue

Citer ce compte rendu

Edgette, J. J. (2006). Compte rendu de [Storytelling: Interdisciplinary and Intercultural Perspectives. By Irene Maria F. Blayer and Monica Sanchez, eds. (New York: Peter Lang, 2002. Pp. xi + 321, ISBN 0-8204-5125-8)]. Ethnologies, 28(2), 225-229. https://doi.org/10.7202/014991ar d'utilisation que vous pouvez consulter en ligne. 
sexuality and body image, and not Barbie. She goes on to explain that Barbie was created to display garments but using human-scale clothing on a doll one sixth the size of a human would cause Barbie's waistband to bulge like a spare tire. "Because fabric of a proportionally diminished gauge could not be woven on existing looms, something else had to be pared down - and that something was Barbie's figure" (228).

Lord defends Mattel's Talking Barbie who stirred up controversy and was yanked from toy store shelves for saying "Math is tough". Contrary to public outcry that insisted this sent a derogatory message to young girls, Lord believes it was a call to study hard and master math because, after all, the doll did not say "Math is tough... for girls".

Although she believes that Barbie is decked out like a parody of her own gender (298), Lord also says "Barbie is an emblem of 'femininity', a concept quite different from biological femaleness" (294). Ultimately, Lord achieves her goal, treating the reader to a behind-thescenes look at the rise of Barbie, the fall of the Handlers, and how a plastic doll has influenced generations of young girls (and boys) in notions of sexuality, femininity, independence and acceptance. Barbie is the projection of wildly different fantasies, and "may be the most potent icon of American popular culture in the twentieth century" (6).

Rhiannon Mckechnie Memorial University of Newfoundland St. John's, Newfoundland

Storytelling: Interdisciplinary and Intercultural Perspectives. By Irene Maria F. Blayer and Monica Sanchez, eds. (New York: Peter Lang, 2002. Pp. xi + 321, ISBN 0-8204-5125-8)

Storytelling consists of an amalgamation of eleven carefully crafted essays that bring together in one volume the collective view of its contributors, resulting in an interesting presentation of their individual perspectives from interdisciplinary and intercultural points of view. Blayer and Sanchez have succeeded in making available to the scholarly community a worthwhile and usable resource to those whose interests lie particularly in the areas of literature, sociology, anthropology, folklore, ethnography, and most relevant, storytelling. Each of the participating authors provides aspects of the story and the storytelling process from 
their own disciplinary training and background. This book furnishes the instructor with a valuable resource that embraces and underscores the interdisciplinary and intercultural underpinnings of the art of storytelling. Generally, there is an overall emphasis on the common vehicle of delivery or focus of presentation, that is, ethnology. Having read each essay the reader cannot help but realize that each is unique in its specific treatment; however, each also presents a practical, applied exercise tightly allied to ethnology. Not only does one become informed about the topic covered, but also one sees the commonality of the linkage to intercultural aspects. Reisman's 1961 sociological study, The Lonely Crowd, put forth the notion that "Storytellers are the indispensable agents of socialization." This reviewer could not help but see this statement illustrated many times throughout Storytelling.

As a professor of folklore, storytelling is one course that I truly enjoy teaching. Many of those who take the course are in-service teachers from widely diverse and varied disciplines. Therefore, I am always looking for new books and other publications that will not only relate to storytelling as process, but also demonstrate the connection between storytelling and culture. In this age of multiculturalism and diversity Blayer and Sanchez have made a credible and important contribution to this end by carefully and deliberately bringing together a relevant and significant set of essays that represents a full range and treatment of differing cultures and disciplines. Ruth Tooze, one of the earlier movers and shakers in the area of storytelling, proposed what the process should entail in her 1959 tome entitled Storytelling wherein she emphasized the process and technique of the art and science of presenting oral narrative. If we look at the Tooze material and couple it with the current volume, we discover the "missing" piece of the picture. When we take the process and connect it to the purpose or reveal its reason for being, then we can better utilize and gain from the experience. The contributing essayists have provided a clear and informative explanation as to the importance for studying, analyzing, and assessing storytelling and providing the connection to both disciplines and cultures alike by illustrating the connection between storytelling and their own discipline.

Stone's use of geography as a means of springboarding into "crossing the borders" into a story is a creative and highly interesting approach to the oral narrative. His blending as a geographer and folklorist results in a clear and articulate map that guides us confidently across the borders. His use of the "passport" metaphor was very clever as it was 
appropriate. This essay successfully illustrates the uniqueness of the culture though adjacent in proximity. Yet, conversely, Sturn's essay clearly and effectively presents the theoretical and conceptual framework that emphasizes the storylistening aspect of storytelling, a part often neglected. His presentation of the theory and his attempt to graphically explain its complexity and structure is remarkably astute. He has succeeded in clarifying that which is abstract and translating it to a more concrete format.

Federici's presentation tackles the issue of interpretation illustrated by using the novels of Eco. Her background in semiotics is obviously revealed as she makes a case for the connection between symbol and communication. Though Marshall McLuhan, in the 1970s, emphasized "medium is the message," Federici makes a very strong argument for the importance of symbol and interpretation as a means to getting at the heart and soul of storytelling as exhibited by the literature selected for demonstrative purposes. DeCosta takes us to the next phase, that of the purely cultural connection or influence. She shows the sociopolitical reflections of a given culture in the literary contributions of that culture. If the storyteller is indeed an agent of socialization, then this essay successfully proves this to be the case. The introduction of testimonial narrative and its complexities is well presented. Her bridging of ethnography and linguistics through narrative is consistent with the overall theme of this volume. DeCosta, too, has been effective in her showing the interdisciplinary and intercultural importance of storytelling.

The next four articles share more in common than did the first four. By noting the titles one can immediately get a sense of a wonderfully seasoned blending of a variety of related and relative components to the areas of interdisciplinary and intercultural emphasis, be it literary or folk. Behrisch engages in a very interesting discussion of the fall of the Victorian hero as traced through the specific narratives by Dickens and Collins. The use of an historical perspective is very effective throughout the essay. Seagos' discourse about gender and fairy tales reminds us of the fact that we must take modernity into consideration when it comes to the subject of storytelling. Her treatment is provocative and raises questions in the mind of the reader that are important to the furthering of knowledge and enlightenment. Her use of the witch figure has a high level of interest. Her analysis and assessment of her topic reflects the thoroughness and accuracy of her research. Virgulti focuses upon the medieval legend to illustrate the folkloric understanding and 
examination of legend and, more specifically, the versions of the same. One cannot help but be reminded of the historic-geographic method that came out of Finland. This essay is insightful and quite accurate in its tracing the transmission and resulting changes to text and narrative over space and time. Wenzowski and Keir-Nicholson combine visual imagery and mental imagery provided by an oral stimulus by relating oral narratives to four specific art works. German expressionism when linked to the Brothers Grimm tales is a remarkable combination. The Jungian inclusion was also an interesting and effective addition. The use of art, folkore, and psychology was masterfully integrated in this essay.

Having arrived at the two essays by Friedberg and Maybin respectively, we are quickly thrust into the arena of linguistic considerations for storytelling. The former makes reference to Himes' research among the Native Americans in the context of oral linguistic markers and presentation. Frieberg has expertly explored and examined this domain in his well-written essay. Maybin takes the next step by concentrating on ten-to-twelve year old children with respect to their conversational narratives. Here once again the author sites the work of Labov to make a case for her perspective. She, too, presents a cogent and interesting analysis of her focus group. Each of these essays, though related to some degree, stands alone in that they each make a strong argument to the reader for the importance of considering these linguistic approaches when engaging in the study of storytelling.

The last essay in this edited volume was written by Swann who has been strategically placed among her colleagues as the perfect closure to the contents of this book. She successfully brings together verbal, visual, and vocal elements of oral narrative at the point of their intersecting. Her inclusion and discussion of context is validly incorporated into her cultural and disciplinary approach. This final essay becomes an appropriate and effective means to bringing to closure a very well presented book that presents a clear and interesting treatment of storytelling emphasizing both interdisciplinary and intercultural perspectives.

In conclusion, Storytelling is a well crafted and organized book that begs for serious consideration for use as a general source relative to storytelling or as a strong reference piece illustrating the apparent value 
of storytelling as it clearly, as it should, demonstrates the importance of interdisciplinary and intercultural perspectives.

This volume is indeed pertinent and appropriate for anyone who has an interest in language and culture. It is an easy, enjoyable, and comfortable read. You will not regret having read Blayer and Sanchez's Storytelling.

J. Joseph Edgette

Widener University

Chester, Pennsylvania

Culinary Tourism. By Lucy M. Long, ed. (Lexington: University Press of Kentucky, 2004. Pp. xiv + 306, ISBN 0-8131-2292-9)

This volume of twelve essays edited by Lucy M. Long brings together an impressive collection of established and emerging foodways scholars. In defining and developing the concept of culinary tourism, it is an important publication.

The book opens with a short foreword by Barbara KirshenblattKimblett and an introductory article by Lucy Long that traces the development of culinary tourism. Long encourages broadening the notion and her definition pushes boundaries. According to Long, culinary tourism is not just food for the tourist, but rather "the intentional, exploratory participation in the foodways of another - participation including the consumption, preparation, and presentation of a food item, cuisine, meal system, or eating style considered to belong to a culinary system not one's own" (21). We engage in culinary tourism at home and in the food court as well as when we travel.

Building on this definition, Long and the other contributors offer several valuable interpretive typologies for types of otherness, foodways, venues for tourism, and strategies for negotiating otherness in cultural tourism (11). For example, in the context of foodways, Long suggests analysing "otherness" along two perpendicular axes: the first runs from Edible/Palatable to Inedible/Unpalatable while the second, intersecting continuum, extends from Exotic to Familiar. These analytic guides provide useful tools. 